\title{
Atividade de formação de professores de matemática mediada pela Atividade Orientadora de Ensino
}

\author{
Math teacher training activity mediated by Teaching-Orienteering \\ Activity
}

Ana Paula Gladcheff Munhoz ${ }^{1}$

Manoel Oriosvaldo de Moura ${ }^{2}$

\begin{abstract}
RESUMO
O objetivo deste artigo é apresentar a Atividade Orientadora de Ensino, por meio dos elementos que a caracterizam, como mediação do processo de formação do professor que ensina matemática. Para isso, tomou-se por base uma pesquisa fundamentada na Teoria da Atividade, na qual foi analisada a significação da atividade de ensino de matemática durante um processo de formação de professores. O pressuposto fundamental é o de que há uma relação entre as ações organizadas durante a atividade de formação e o processo de significação da atividade de ensino dos professores, o que torna possível compreender o quanto essas ações são orientadoras de tal processo. A atividade de formação desencadeouse por uma proposição aos professores para desenvolverem atividades de ensino, organizados em pequenos grupos e orientados pelos princípios teórico-metodológicos da Atividade Orientadora de Ensino. Esta, por adquirir força mobilizadora, tornou-se uma atividade específica na perspectiva formulada por Leontiev, podendo ser caracterizada como mediadora no processo de significação da atividade de ensino.
\end{abstract}

Palavras-chave: Ações formadoras. Atividade Orientadora de Ensino. Formação de professores. Mediação. Teoria histórico-cultural.

\begin{abstract}
The purpose of this paper is to present the Teaching-Orienteering Activity, through the elements that characterize it, as a mediation of the teacher education process that teaches mathematics. For this, it was guided by a research reasoned in the Activity Theory, in which the significance the mathematics teaching activity during a teacher training process was analyzed. The fundamental assumption is that there is a relationship between the actions organized during the training activity and the process of signifying the teachers teaching activity, which makes it possible to understand how these actions are guiding this process. The training activity was triggered by a proposition for teachers to develop teaching activities, organized in small groups and guided by the theoretical and methodological principles of the Teaching-Orienteering Activity. This, by acquiring mobilizing force, became a specific activity in the perspective formulated by Leontiev, and can be characterized as a mediator in the process of signifying the teaching activity.
\end{abstract}

Keywords: Forming actions. TeachingOrienteering Activity. Teacher training. Mediation. Cultural historical theory.

\footnotetext{
${ }^{1}$ Doutora em Educação pela Universidade de São Paulo (FEUSP). Área de concentração: Ensino de Ciências e Matemática; Pós.doutora em Educação pela Universidade Federal de São Carlos (UFSCar). Linha de pesquisa: Educação em Ciências e Matemática. https://orcid.org/0000-00028281-4651. E-mail: anapaula.glad@alumni.usp.br.

${ }_{2}^{2}$ Professor Titular da Faculdade de Educação da Universidade de São Paulo. Área de atuação: Educação Matemática com foco em metodologia de ensino e formação de professores. Docente do programa de pós-graduação e do curso de graduação da Faculdade de Educação da USP. Líder do Grupo de Estudos e Pesquisas sobre Atividade Pedagógica - GEPAPe. Brasil.
} https://orcid.org/0000-0002-0431-4694. E-mail: modmoura@usp.br. 


\section{Introdução}

Neste artigo, temos o propósito de apresentar a Atividade Orientadora de Ensino, por meio dos elementos que a caracterizam, como mediação do processo de formação do professor que ensina matemática. Esse processo é entendido como significação, interpretada por Leontiev (1983, p. 225, tradução nossa) como "a forma em que um homem determinado chega a dominar a experiência da humanidade", tornando consciente, para si, o reflexo generalizado da cultura humana que se apresenta sob a forma de objetos, conceitos, condutas ou saberes. Destacamos aqui a significação da atividade de ensino em uma proposta de formação, a depender das ações que a constituem.

Para cumprirmos o nosso propósito, pautamonos em uma pesquisa concluída no ano de 2015, fundamentada na Teoria da Atividade e ancorada nos pressupostos da Teoria histórico-cultural. Por meio dessa investigação, analisamos o processo de significação da atividade de ensino de matemática que pode emergir durante uma atividade de formação contínua, realizada com professores que ensinam matemática nos anos iniciais do Ensino Fundamental I.

O conceito fundamental que norteou a pesquisa foi o de atividade, formulado por Leontiev (1978 p. 315, grifos do autor), assim compreendida: "processos psicologicamente caracterizados por uma meta a que o processo se dirige (seu objeto) coincidindo sempre com o objetivo que estimula o sujeito a executar esta atividade, isto é o motivo". A pesquisa, por sua vez, é parte de um projeto de formação de professores organizado e realizado como um projeto de pesquisa em rede ${ }^{3}$, composto por quatro núcleos de investigação, que interagiam, coordenados por pesquisadores de diferentes universidades públicas no Brasil, e desenvolvido no decorrer de quatro anos. Um dos núcleos, o da Faculdade de Educação da Universidade de São Paulo, caracterizou-se como o campo empírico para a nossa pesquisa sobre ações realizadas em uma atividade de formação contínua de professores que ensinam matemática. Em especial, aquelas ações que

\footnotetext{
${ }^{3} \mathrm{~A}$ investigação que fundamenta este artigo fez parte de um projeto de pesquisa em rede e contou com financiamento do Programa Observatório da Educação da CAPES. Este programa, tal como afirmam seus gestores, tinha a finalidade de fomentar estudos e pesquisas em educação, visando proporcionar a articulação entre pós-graduação, licenciaturas e escolas de Educação Básica. Obutchénie: R. de Didat. e Psic. Pedag.|Uberlândia, MG|v.4|n.2|p.355-381|maio/ago. 2020 ISSN: 2526-7647 
possuem potencial para desenvolver o pensamento teórico dos professores, possível de ser revelado na articulação entre a teoria e a prática, na constituição da práxis pedagógica que os envolve em uma atividade coletiva.

Partimos da hipótese de que o processo de significação da atividade de ensino pode emergir na atividade de formação contínua, em que os significados conceituais, tidos como seus referenciais, podem ser apropriados pelos professores, em sua relação com as ações organizadas no desenvolvimento da atividade. Portanto, o pressuposto fundamental é o de que há uma relação entre as ações organizadas durante a atividade de formação e o processo de significação da atividade de ensino dos professores, o que torna possível compreender essas ações como orientadoras de tal processo.

O destaque que aqui fazemos é dado por uma especial ação, desenvolvida no decorrer da atividade de formação e desencadeada por uma proposição aos professores, que, reunidos em pequenos grupos e orientados pelos princípios teórico-metodológicos da Atividade Orientadora de Ensino, deveriam organizar atividades de ensino.

A Atividade Orientadora de Ensino, proposta inicialmente por Moura (1996) e caracterizada por elementos da Teoria da Atividade, é compreendida como uma base teóricometodológica "direcionada especificamente para a reconstituição de uma atividade humana em seus traços essenciais e necessários, nos processos de ensino e aprendizagem" (NASCIMENTO, 2014, p. 277). Os princípios teórico.metodológicos que a regem, explicitam na como a unidade entre a atividade de ensino (do professor) e a atividade de aprendizagem (do estudante), no contexto da atividade pedagógica. Essa atividade, segundo o autor, deve estar organizada de modo a permitir a interação entre sujeitos que, diante de uma situação-problema, compartilham significados de conceitos necessários para a solução do problema que os mobiliza para resolvê-lo (MOURA, 2012). Possibilita, dessa forma, que os sujeitos atribuam sentido às suas ações durante o movimento de apropriação dos significados sociais desenvolvidos pela experiência da humanidade e sintetizados nos conceitos.

Uma particularidade extremamente relevante que constitui a Atividade 
Orientadora de Ensino é a intencionalidade pedagógica, que proporciona ao ambiente educativo atenção às diferenças individuais, às particularidades do problema colocado em ação e aos vários conhecimentos presentes, com o objetivo de formar sujeitos na direção social de formação humana que possui o coletivo como referência. E isso, segundo Moura (2012), imprime uma responsabilidade ímpar aos que organizam o ensino.

Para este artigo, como já mencionado, apresentamos as ações propostas para desenvolver atividades de ensino, que se configurou como central no processo de formação. Por adquirir força mobilizadora própria, tornou.se uma atividade específica na perspectiva formulada por Leontiev e, como já evidenciado, orientada pelos princípios teórico-metodológicos da Atividade Orientadora de Ensino que, por sua vez, pode ser caracterizada como mediadora nesse processo de significação da atividade de ensino.

Nesse contexto de formação, subgrupos foram organizados e deveriam eleger um conceito a ser ensinado pelos professores em sua prática educativa. Essa, portanto, torna.se uma situação.problema para os professores, chamados a criar coletivamente, para a atividade planejada, uma situação desencadeadora de aprendizagem que, por sua vez, requer ações de ensino que objetivam mobilizar os alunos a fim de que se coloquem em atividade de aprendizagem (MOURA et al., 2010). É por meio desse movimento que os professores explicitam a forma como organizam o ensino, e revelam se suas ações assumem a perspectiva teórico. metodológica proposta na atividade de formação.

\section{A atividade de formação contínua na perspectiva da Teoria da Atividade}

$\mathrm{Na}$ Teoria histórico-cultural, que fundamenta este estudo, a premissa é que o homem se torna humano, ao apropriar.se do saber historicamente produzido pela humanidade. Mediado pela comunicação nas relações entre os seres humanos necessárias para o trabalho, esse processo de apropriação é considerado um processo de aprendizagem (ou processo de educação) (LEONTIEV,1978) e, de acordo com Smolka (2000), vincula-se ao processo de internalização proposto por Vigotski (2009), ao estabelecer que as relações intrapsíquicas se constituem a partir das relações 
interpsíquicas. Na interpretação de Smolka (2000), o conceito de internalização deve ser compreendido como apropriação presente na obra marxista, como um fazer e usar instrumentos, o que significa, nesse caso, não "uma questão de posse, de propriedade, ou mesmo de domínio, individualmente alcançados, mas é essencialmente uma questão de pertencer e participar nas práticas sociais" (SMOLKA, 2000, p. 37). E, como ressalta Araujo (2009, p. 5, grifo da autora), na

[...] "reconstrução interna de uma operação externa", que tem uma dinâmica essencialmente dialógica e, segundo Vygotsky, segue um percurso de transformações iniciado com a reconstrução interna de uma atividade externa. O processo interpessoal transforma-se em um processo intrapessoal, tendo como contexto as relações estabelecidas entre sujeitos historicamente constituídos, campo por excelência da mediação.

Corroborando as afirmações das autoras supracitadas, consideramos a inter.relação entre desenvolvimento e aprendizagem pela educação escolar. Nessa perspectiva, também nos apoiamos em Vigotski (2004, p. 484), quando nos afirma que "a aprendizagem não é desenvolvimento, mas, corretamente organizada, conduz o desenvolvimento mental da criança, suscita para a vida uma série de processos que, fora da aprendizagem, se tornariam inteiramente inviáveis”.

Nessa direção encontra.se o objetivo do processo educativo na perspectiva da Teoria histórico-cultural, dado por socializar o saber historicamente produzido pela humanidade. Organizado de maneira adequada, torna.se capaz de impulsionar o desenvolvimento humano em sintonia com o movimento histórico e social que o constitui. Assim, entendida como uma via para o desenvolvimento psíquico e principalmente humano, a educação escolar possui a função primordial de "produzir, direta e intencionalmente, em cada indivíduo singular, a humanidade que é produzida histórica e coletivamente pelo conjunto dos homens” (SAVIANI, 2011, p. 13), ou seja, de socializar o "saber historicamente produzido tendo em vista a máxima humanização dos indivíduos" (MARTINS, 2007, p. 24). No entanto, tal movimento não se restringe à ação do professor ou à do aluno, mas ao processo como um todo, considerando as duas dimensões, o ensino e a aprendizagem - uma unidade, como essência da atividade pedagógica (MOURA, 2017). O professor, com o objetivo de ensinar, e o aluno, com a finalidade de aprender, têm seu ponto de 
encontro no espaço de aprendizagem, compreendido como aquele onde os sujeitos aprendem, mediados por uma atividade de ensino (CEDRO; MOURA, 2007).

Dentro desse contexto estão a finalidade e a essência do trabalho do professor, sujeito da atividade mediadora que tem por objetivo a apropriação do conhecimento científico pelos alunos, por meio de ações organizadas para esse fim (MOURA; ARAUJO, 2018). Isso significa, de acordo com Duarte (1993), que o professor, por meio de seu trabalho, possui uma ação mediadora entre a formação do aluno na vida cotidiana, em que ele se apropria, de forma espontânea, da linguagem, dos objetos, dos usos e costumes, e a formação do aluno nas esferas não cotidianas da vida social, que lhe permite o acesso a objetivações, tais como a ciência e a arte.

Entendemos que a mediação entre o ensino e a aprendizagem de um conceito é uma atividade que tem como objeto um conceito presente na situação-problema escolhida como situação desencadeadora de aprendizagem, intencionalmente criada ou identificada pelo professor como mobilizadora da atividade de aprendizagem dos estudantes. A Atividade Orientadora de Ensino (AOE) é, portanto, uma atividade mediadora entre a atividade de ensino (do professor) e a atividade de aprendizagem (do estudante), ou seja, constitui-se como mediação entre sujeito e objeto, tal como defende Leontiev (1983, p. 105), ao se referir à mediação como atividade.

Este, portanto, é o trabalho do professor: a atividade de ensino que se dá pela organização do ensino na perspectiva dialética da relação entre teoria e prática e que, por sua vez, é composta por ações, uma delas o estudo sobre o conhecimento teórico do conceito e sua articulação com a prática educativa. Esta última pode ser desenvolvida durante um processo de formação contínua e pode ser entendida como "um processo que ocorre na continuidade da formação inicial e que visa à transformação da realidade escolar por meio da articulação entre teoria e prática docente" (MORETTI, 2007, p. 24), organizado de forma a oportunizar a significação da atividade de ensino do professor.

No entanto, para que isso ocorra, defendemos que a formação seja estruturada como uma atividade na perspectiva leontieviana, considerando suas dimensões indissociáveis: a de orientação, constituída pelo objeto, pela necessidade e pelo motivo; e a de execução, que se refere às ações, às operações e aos objetivos. Davidov (1988, p. 
28, tradução nossa) afirma que a distinção entre uma atividade e outra é dada essencialmente por seu objeto, o que significa “... aquilo pelo qual está dirigido o ato..., ou seja, como algo com o que o ser vivo se relaciona, como o objeto de sua atividade...”. Daí a importância de termos a organização do ensino como uma atividade e a defesa da Atividade Orientadora de Ensino como mediação entre a atividade de ensino e a de aprendizagem. Isso nos permite compreender que o objeto de uma atividade de formação contínua deve ser a apropriação do significado de atividade de ensino. Os conceitos, as ações e as operações por meio das quais a atividade se realiza, podem ser considerados como seus componentes fundamentais. Dessa forma, podemos perceber o quão importantes são as ações organizadas e realizadas de modo colaborativo durante uma atividade de formação contínua, pois é nesse movimento, como atividade, que o processo de significação da atividade de ensino do professor pode ser desencadeado. E a estruturação da atividade de formação (com foco na organização e nas ações praticadas) deve ter uma relação direta com a organização do ensino (desenvolvida pelos professores). Esta relação encontra.se exposta na Figura 1, a seguir.

Figura 1 - Unidades de análise na atividade de formação contínua

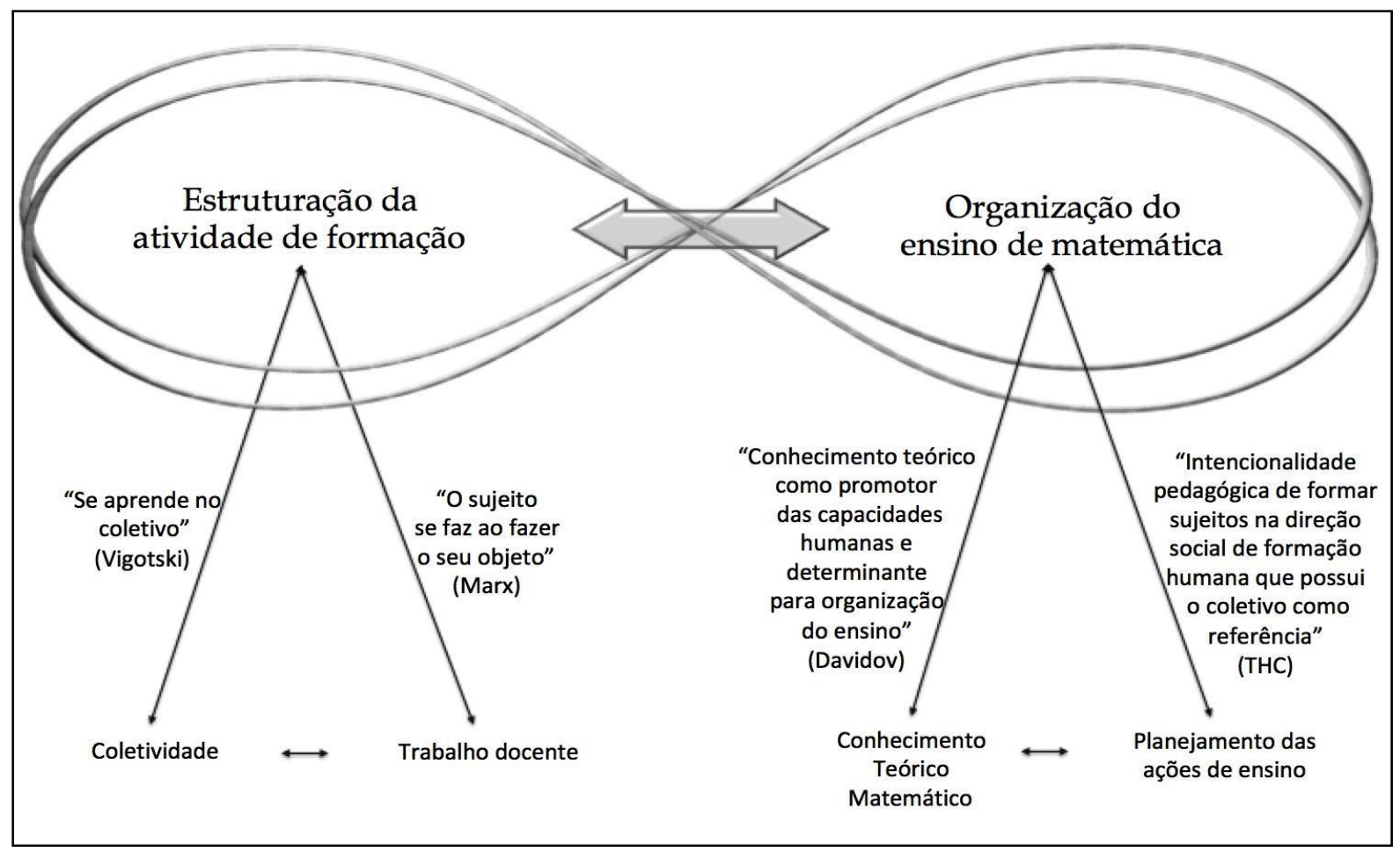

Fonte: Adaptado de Gladcheff (2015, p. 226) 
A Figura 1 representa a nossa compreensão da estruturação da atividade de formação e da organização do ensino como uma unidade para a atividade de formação contínua. Isso porque esses dois elementos, definidos em nossa pesquisa como nossas unidades de análise, foram analisados simultaneamente, com o objetivo de destacarmos as ações que possuem o potencial para que o processo de significação da atividade de ensino de matemática possa ser desencadeado. A significação trilhada na direção do significado socialmente construído para a atividade pedagógica, em nossa perspectiva, dado pela compreensão da educação escolar como via para o desenvolvimento psíquico humano.

A estruturação da atividade de formação, que possui uma organização baseada nos pressupostos da Teoria da Atividade, corrobora os pressupostos de Vigotski (2009) e de Marx (2002) sobre o papel do trabalho em coletividade no desenvolvimento humano.

As produções de Davidov (1988) e de Vigotski (2009) sobre desenvolvimento e aprendizagem demonstram que a apropriação do conhecimento teórico na direção do desenvolvimento do sujeito é considerada o objetivo essencial no processo educativo, pois, como já afirmamos, para se apropriar de um novo conceito, o sujeito primeiro se relaciona com ele por meio das atividades sociais (interpsíquico), para depois tomá-lo para si (intrapsíquico). Nestes estudos é que fundamentamos a premissa de que se aprende no coletivo, e vale aqui ressaltar que, para Vigotski, na leitura de Holzman (2002, p. 98),

[...] as atividades dos seres humanos, em todos os estágios de desenvolvimento e organização, são produtos sociais e precisam ser vistos como desenvolvimentos históricos, não como meros desenvolvimentos interpessoais. $O$ social não se reduz ao interpessoal; a atividade social não é mera interação social.

Marx (2002, p. 211), ao identificar o trabalho como um processo em que, com sua própria ação, o homem "impulsiona, regula e controla seu intercâmbio material com a natureza", coloca para nós, professores, a necessidade de identificarmos o nosso objeto de trabalho, aquele para o qual a ação se dirige e objetiva o antes idealizado. Entendemos que, no caso da educação escolar, o mais evidente como objeto central do professor é possibilitar, por meio da atividade de ensino, a 
apropriação de conceitos tidos como relevantes para a formação do seu aluno. Não qualquer ensino, diria Vigotski, mas, sim, aquele que promove o desenvolvimento (VYGOTSKI, 1991). Esse pressuposto de Vigotski nos impõe considerar que nosso objeto é a atividade de ensino que promova a formação do pensamento teórico dos estudantes (DAVIDOV, 1988). Fica evidente que é atividade central do professor ter presente que seu trabalho é atividade, na acepção leontieviana. Atividade que se estrutura como trabalho, impulsionada para um determinado fim, com ações realizadas com instrumentos e condições objetivas da sociedade em que se realiza. E dessa maneira podemos ter presente a complexidade da atividade do professor, se assumirmos o que sinteticamente nos diz Leontiev (1983, p. 129, tradução nossa), ao analisar os processos de formação da consciência humana: "a atividade do homem constitui a sua consciência". Assim, fica evidente que o objeto do professor é dos mais complexos, pois lida com o conceito impresso na palavra, na linguagem, e já distante do seu processo de significação.

Ao aceitarmos as premissas de Leontiev sobre a atividade, que tem seu nascedouro no conceito de trabalho de Marx (DAVIDOV, 1988, p. 38), entendemos estar nela a fonte do desenvolvimento humano, e, sendo assim, também é a unidade de análise de seu desenvolvimento. Portanto, ao analisarmos a atividade do professor, inferimos ser esta a fonte para entender sua formação, que poderá ser compreendida pela análise do que realiza como atividade, para objetivar aquilo que antes idealizara em forma de um plano de ensino. Essa é a justificativa para considerarmos o ensino como atividade de formação contínua do professor.

Assim, como parte fundamental da atividade de formação do professor que ensina matemática, uma ação pode ser considerada central no movimento formador: desenvolver atividades de ensino de conceitos matemáticos, fundamentadas na perspectiva de um ensino que impulsione o desenvolvimento psíquico e as capacidades humanas. E, no caso de nossa pesquisa, fazemos uma relação com o conhecimento teórico matemático e o planejamento das ações de ensino, fundamentados nos estudos de Davidov (1988) e nos pressupostos da Teoria histórico-cultural. Inferimos, pelos pressupostos aqui assumidos, que essas ações podem transformar.se em atividades. A ação, quando orientada para 
organizar o ensino que promove o desenvolvimento do aluno, passa a constituir uma atividade específica dentro da formação: a atividade dirigida para a apropriação do conhecimento teórico como promotor do desenvolvimento das capacidades humanas, que possui o coletivo como referência.

Essas são consideradas as premissas que orientam o processo de formação, em conjunto com seus elementos considerados essenciais a serem incorporados pela atividade, tendo como referência a perspectiva de Leontiev (1983).

\section{A Atividade Orientadora de Ensino como mediadora do processo de significação}

No movimento de formação, destacamos o papel atribuído à Atividade Orientadora de Ensino (AOE) como mediadora na relação indissociável entre os processos de ensino e aprendizagem, no contexto da atividade pedagógica.

Proposta inicialmente por Moura (1996, 2012), como mediação na educação escolar, a AOE está fundamentada na teoria da atividade, considerados os pressupostos sobre apropriação de conceitos de Davydov (1982). Esta possui princípios teórico-metodológicos estruturados de modo a permitir que sujeitos interajam, mediados por um conteúdo, e compartilhem significados, com o objetivo de solucionar coletivamente uma situação. problema. É considerada orientadora porque

[...] define os elementos essenciais da ação educativa e respeita a dinâmica das interações que nem sempre chegam a resultados esperados pelo professor. Este estabelece os objetivos, define as ações e elege os instrumentos auxiliares de ensino, porém não detém todo o processo, justamente porque aceita que os sujeitos em interação partilhem significados que se modificam diante do objeto de conhecimento em discussão. (MOURA, 2012, p. 155)

Os elementos que caracterizam a $\mathrm{AOE}$ como mediação no processo de significação da atividade de ensino de matemática, que pode emergir durante a atividade de formação contínua, ao serem considerados orientadores para o processo de desenvolvimento das atividades de ensino para conceitos matemáticos, fazem com que assumamos a centralidade da AOE no movimento formador. Isso porque, em sua formulação, tal conceito mantém a estrutura de 
atividade proposta por Leontiev, ao "indicar uma necessidade (apropriação da cultura), um motivo real (apropriação do conhecimento historicamente acumulado), objetivos (ensinar e aprender) e propõe ações que considerem as condições objetivas da instituição escolar" (MOURA et al., 2010, p. 217).

Assim, a AOE, “[...] que pode ser entendida como a mediação entre a atividade de ensino voltada para a satisfação de uma 'necessidade' do professor e a atividade do estudante mobilizado para se apropriar da experiência social da humanidade" (MOURA; ARAUJO, 2018, p. 212), possibilita ao professor, por seu desenvolvimento, realizar e compreender seu objeto de estudo: o processo de ensino de conceitos. E aqui nos valemos, também, do conceito de mediação como interpretado por Martins (2012, p. 3), ou seja, como uma "interposição que provoca transformações, encerra intencionalidade socialmente construída e promove desenvolvimento, enfim, uma condição externa que, internalizada, potencializa o ato do trabalho, seja ele 'prático' ou 'teórico' ”.

$\mathrm{Na}$ atividade de formação, a AOE medeia o desenvolvimento das atividades de ensino, ao ser executada a tarefa proposta aos professores, já mencionada: organizar o ensino, colaborativamente, e orientados pelos princípios teórico-metodológicos da Atividade Orientadora de Ensino. Esse movimento está representado na Figura 2. 
Figura 2 - Movimento concretizado pela tarefa dada aos professores: organizar o ensino

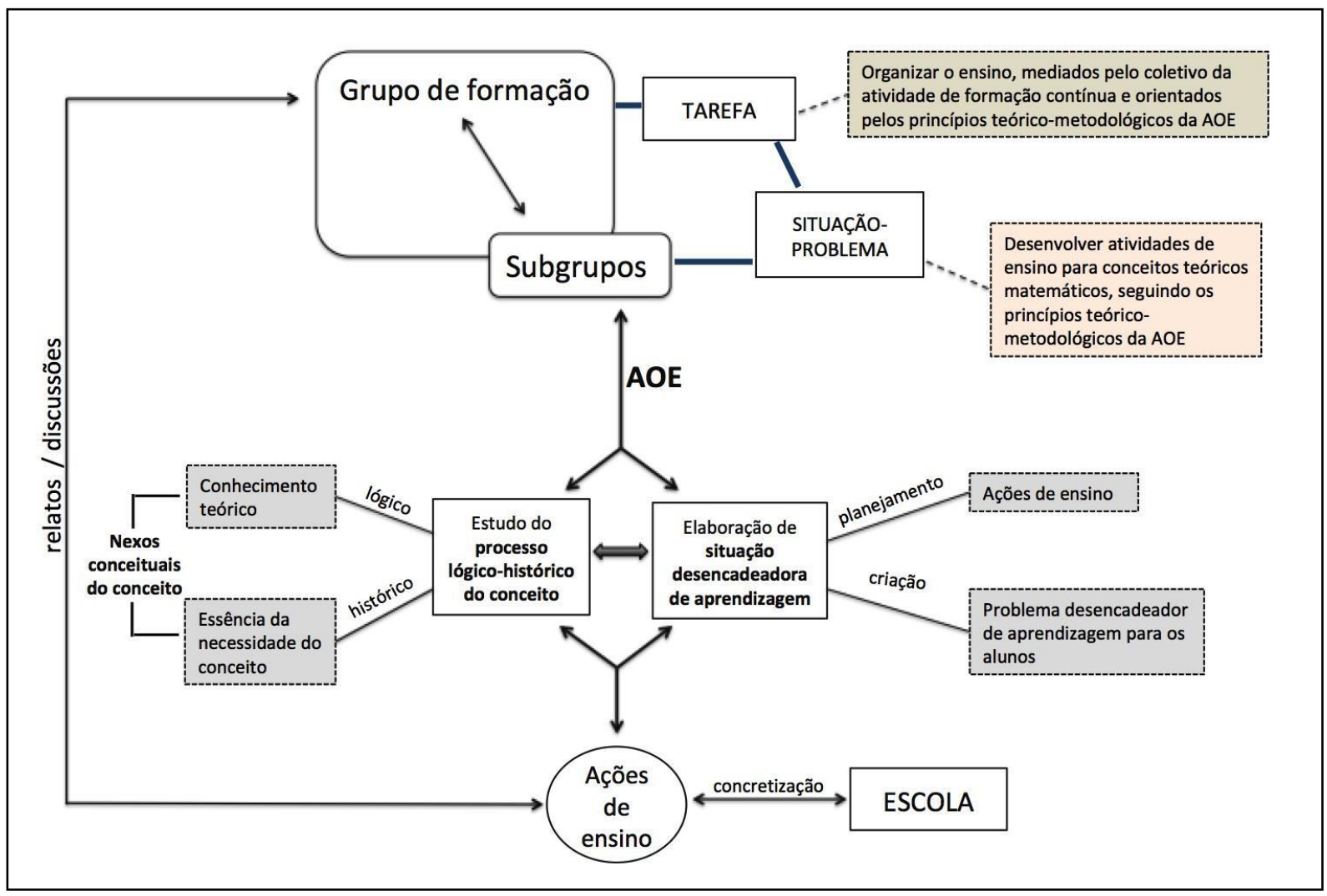

Fonte: Adaptado de Gladcheff (2015, p.194)

O movimento, sistematizado na Figura 2, representa o modo como os professores foram organizados e orientados para a solução do que se tornou uma situação.problema para eles, no movimento formador. Traz como enfoque a formação do pensamento teórico dos professores, possível de ser revelado na articulação entre a teoria e a prática, na constituição da práxis pedagógica que os envolva em uma atividade coletiva.

Ao destacarmos a coletividade como premissa para a aprendizagem durante uma atividade de formação, compreendemos a necessidade de assegurar aos professores propostas de situações nas quais o compartilhamento das ações se torna necessário para o seu desenvolvimento intelectual. A colaboração, que faz parte do trabalho coletivo, pressupõe o desenvolvimento de ações com base em objetivos comuns, e os professores, dessa forma, podem transformar a maneira como tratam o objeto da atividade. Ao tomarem consciência das relações entre o trabalho coletivo e o objeto de estudo, o compartilhamento das ações pode se 
transformar em um modo geral de ação, tornando.se, segundo Polinova (1996, p. 151), "uma espécie de modelo de conteúdo da estrutura cognitiva".

Para isso, o grupo de formação foi dividido em subgrupos de quatro a seis componentes, cada qual com a tarefa de desenvolver atividades de ensino para um determinado conceito matemático. $\mathrm{Na}$ sistematização exposta pela Figura 2, estão presentes os princípios que regem a $\mathrm{AOE}$ e que serviram como elementos mediadores no processo. O desafio para os professores é, portanto, o de organizar ações de ensino, que não se limitem

[...] simplesmente a reforçar o desenvolvimento do pensamento empírico, posto que se trata de um tipo de pensamento pautado nos aspectos externos e observáveis dos objetos e fenômenos e, como tal, desenvolve-se independentemente da escolarização do sujeito. (ROSA; MORAES; CEDRO, 2010, p. 80)

Com essa finalidade, os professores iniciam seus estudos, percorrendo, eles mesmos, a gênese ou a história do conceito a ser trabalhado com seus alunos, para, com isso, revelar o que compreendemos pelos nexos conceituais (ou nexos internos) do conceito. Estes, por sua vez, associam.se ao lógico.histórico do objeto estudado, representando o aspecto essencial do conceito e, neste caso, "estão impregnados de história, por isso, são históricos" (SOUSA; MOURA, 2016, p. 2). Contêm a "lógica, a história, as abstrações, as formalizações do pensar humano no processo de constituir-se humano pelo conhecimento" (SOUSA et al., 2014, p. 96).

Kopnin (1978) ressalta que o histórico consiste no processo de mudança do objeto, nas etapas de seu surgimento e desenvolvimento, e o lógico sistematiza o meio pelo qual o pensamento realiza essa tarefa no processo de reflexão sobre o histórico, de forma a refletir os principais períodos da história de tal objeto. Portanto, o movimento histórico do conceito, explicitado em seu processo lógico. histórico, manifesto nas situações.problema vivenciadas pela humanidade, apresenta a essência das necessidades humanas que motivaram a produção de tal conceito e que também requereu a sua sistematização lógica. A lógica, neste caso, como lógica dialética, pela qual "se estuda, sobretudo, o conteúdo mental expresso na forma linguística, dando atenção especial à relação desse conteúdo com a 
realidade objetiva no próprio processo de pensamento, ou seja, no próprio processo de aquisição do conhecimento" (DIAS; SAITO, 2009, p. 9).

Com a objetivação da compreensão desse movimento, entendido como o processo lógico-histórico do conceito, os professores passam a entender a história da matemática como um instrumento de apoio ao ensino e estabelecem uma nova relação com o conhecimento, olhando a ciência "como um organismo vivo, impregnado de condição humana, com as suas forças e as suas fraquezas" (CARAÇA, 2010, p. vii) e historicamente construída como produto de interesses e necessidades sociais. E é com essa concepção, como instrumento em uma dimensão de ferramenta simbólica, que entendemos ser necessária a sua apropriação por parte dos que integram a escola. Acreditamos nessa possibilidade, ao considerarmos a interface entre a história da Matemática e a Educação, para além de uma revisão historiográfica, buscando, no processo lógico-histórico, o movimento do pensamento no contexto da formação do conceito estudado.

Continuando o processo, os professores, fundamentados nos estudos sobre o movimento lógico.histórico do conceito, planejam, em grupos, situações.problema organizadas em situações desencadeadoras de aprendizagem que podem ser materializadas como: um jogo com propósito pedagógico, que preserva o caráter de problema; uma problematização de situações emergentes do cotidiano, que oportuniza colocar o aluno diante da necessidade de vivenciar a solução de problemas significativos para ele; ou uma história virtual do conceito, que coloca o aluno diante de uma situação-problema semelhante à vivida pelo homem (no sentido genérico) (MOURA, 2012). É importante ressaltar, no caso da história que envolve a situação desencadeadora, que não se trata de uma "história factual, mas sim aquela que está impregnada no conceito ao considerar que esse conceito objetiva uma necessidade humana colocada historicamente" (MORETTI; MOURA, 2011, p. 443).

Para que o conceito seja apropriado pelo aluno, recordemos o que nos diz Leontiev (1978), ao enfatizar a complexidade desse processo. É preciso, segundo o autor, que seja desenvolvida uma atividade que reproduza os traços essenciais da atividade humana que gerou o conceito. Portanto, a situação desencadeadora de aprendizagem deve 
[...] contemplar a gênese do conceito, ou seja, a sua essência; ela deve explicitar a necessidade que levou a humanidade à construção do referido conceito, como foram aparecendo os problemas e as necessidades humanas em determinada atividade e como os homens foram elaborando as soluções ou sínteses no seu movimento lógico-histórico. (MOURA et al., 2010, p.103.104)

Como parte fundamental à situação desencadeadora de aprendizagem, são planejadas ações de ensino que orientam os alunos à solução do problema que ela propõe, colocando o conceito em movimento para que seja apropriado por eles. $\mathrm{O}$ que se constitui como problema na situação desencadeadora de aprendizagem é considerado um problema de aprendizagem, tal como o define Rubtsov (1996). E o aluno, ao resolvê-lo, apropria-se de uma forma de ação geral, que se torna base de orientação das ações em diferentes situações que o cercam, e não um problema concreto prático que, por sua vez, busca modos de ação em si e cuja resolução serve somente para uma situação específica, particular.

O que foi planejado coletivamente é levado pelo professor à sua prática educativa, como uma ação individual, para, com ela, modificar o pensar de seus alunos, mas também aprender e transformar seu conhecimento e a si mesmo, num processo dialético. Em seguida, como um movimento contínuo, volta ao grupo para refletir e avaliar o vivenciado na escola, mediado pelo coletivo proporcionado na atividade de formação, trazendo mudanças na atividade de ensino desenvolvida.

Entendemos que esse modo de desenvolvimento, que permitiu aos professores apropriar.se de conceitos matemáticos, em sua forma teórica, é fundamental na transformação de suas ações. Possibilita autonomia para que trabalhem os conceitos por meio de atividades de ensino, para o desenvolvimento do pensamento teórico nos estudantes, e permite que a formação não seja descolada "dos condicionantes impostos pela realidade objetiva na qual realizam o seu trabalho" (SOUZA; ESTEVES, 2018, p. 671). Por isso, os professores, coletivamente, significam sua atividade de ensino, alternando momentos de reflexão teórica e ação prática em seu trabalho docente.

Voltemo.nos agora para o que representa a Figura 3, como um modelo teórico das relações essenciais da organização do ensino, em uma atividade de 
formação contínua em matemática que visa ao desenvolvimento do pensamento teórico do professor.

Figura 3 - Modelo teórico das relações essenciais da organização do ensino em uma atividade de formação contínua em matemática

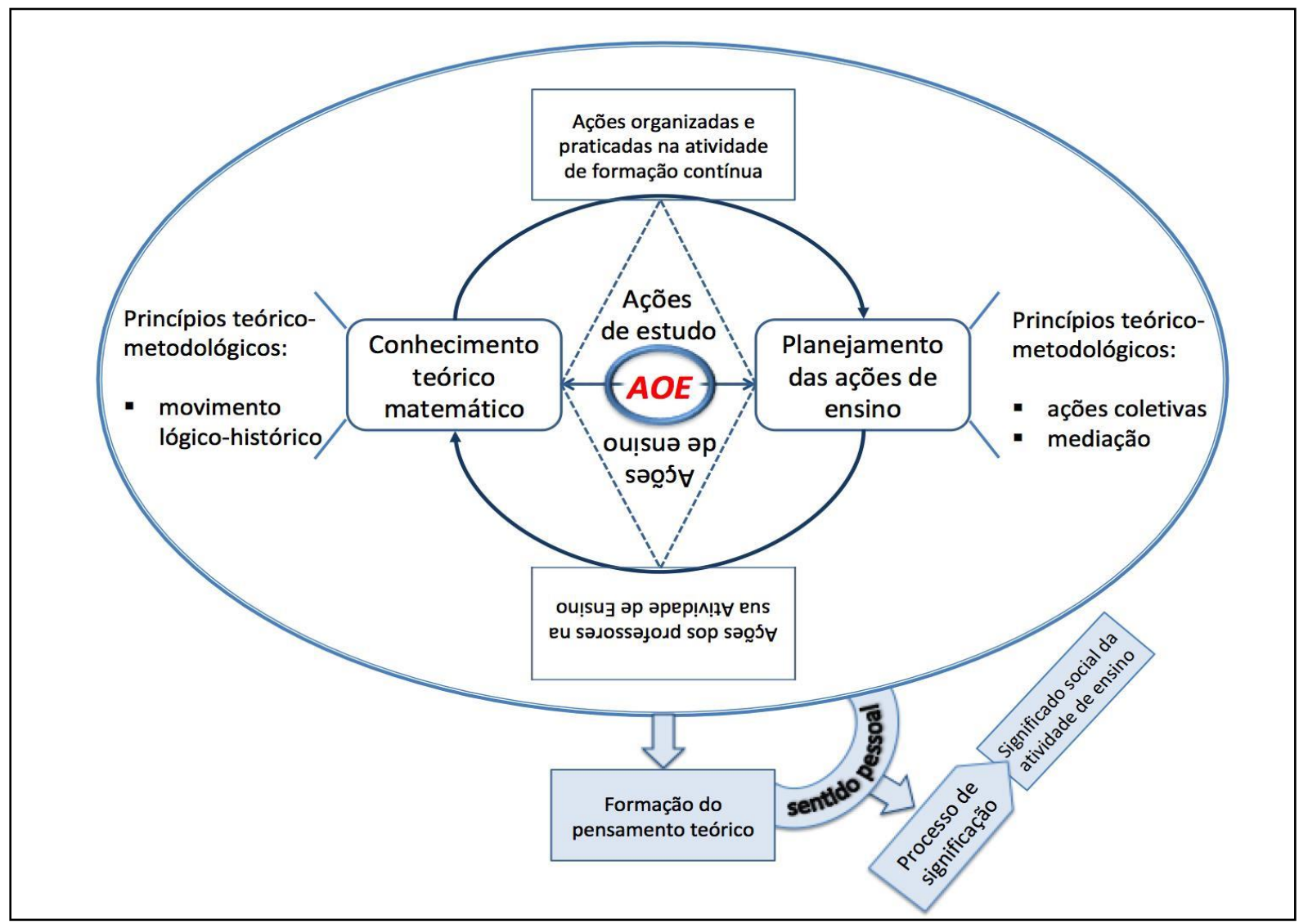

Fonte: Gladcheff (2015, p.87)

Com esse modelo expresso na Figura 3, procuramos representar o movimento de formação do pensamento teórico do professor na atividade de formação. A AOE, nesse contexto, é atividade do professor que, ao agir na direção da apropriação de novos nexos conceituais constitutivos do conhecimento teórico matemático (ações de estudo), incorpora.os no planejamento de suas ações de ensino. E assim, por uma mesma concepção, o movimento lógico.histórico do conceito pode ser proposto como uma perspectiva didática para o ensino de matemática (SOUSA, 2018).

As ações de estudo, fundamentadas nos princípios teórico-metodológicos da AOE, orientadas pelas ações organizadas e praticadas na atividade de formação, podem se constituir como modos de estudo, a fim de que as ações coletivas se 
configurem como conteúdo e modo geral de ação para as ações do professor em sua atividade de ensino. Isso significa que as ações de ensino do professor incorporam, de maneira singular, as ações coletivas praticadas na atividade de formação, influenciadas pela relação que ele desenvolve com o conhecimento teórico matemático e o planejamento de suas ações de ensino.

O conhecimento teórico matemático, considerando o movimento lógico.histórico dos conceitos como apreendedor da essência do movimento conceitual e histórico do conhecimento produzido pela humanidade; e o planejamento das ações de ensino, como parte essencial na organização do ensino e orientado pela intencionalidade pedagógica de formar sujeitos na direção social de formação humana que possui o coletivo como referência, constituem.se, dessa forma, em uma relação de unidade entre as ações de estudo e as ações de ensino do professor, mediada pelos princípios teórico-metodológicos da Atividade Orientadora de Ensino.

O movimento descrito possibilita o desenvolvimento do pensamento teórico do professor, com o intuito de incidir no sentido pessoal que ele atribui ao ensino, e faz emergir o processo de significação que esperamos convergir para o significado social da atividade de ensino, proposto na atividade de formação.

Aqui ressaltamos que, em nossa compreensão, baseados nos estudos de Leontiev (1978), os termos significação e significado social não se constituem em sinônimos. Entendemos que o significado social, como algo mais estável, está relacionado à função socialmente estabelecida a um objeto cultural, seja ele material ou não material; o sentido pessoal diz respeito ao que este objeto cultural significa para o sujeito; e a significação encontra-se no fenômeno, é o modo de perceber as coisas que nos constitui e é, portanto, interpretada pelo processo pelo qual o homem se conscientiza do mundo que o rodeia (GLADCHEFF, 2015). Nas palavras de Leontiev (1983, p. 125, tradução nossa):

[...] Se a sensitividade externa relaciona na consciência do sujeito as significações com a realidade no mundo objetivo, o sentido pessoal as relaciona com a realidade de sua própria vida dentro deste mundo, com suas motivações. $\mathrm{O}$ sentido pessoal é também o que origina a parcialidade da consciência humana. 
Retornando ao que o movimento descrito anteriormente nos indica, podemos afirmar que o professor que se encontra em atividade, no movimento de formação, passa a atribuir à sua atividade de ensino um sentido diferente do que um outro professor atribui. No entanto, compreendemos que não é "qualquer" forma de organização que sustentará a atribuição de sentido às ações que possuem potencial para desencadear o processo de significação. É preciso que a significação convirja para o significado social da atividade de ensino fundamentado na teoria histórico-cultural e, para isso, defendemos a necessidade de o desenvolvimento das atividades de ensino estar integrado a um processo de formação estruturado como atividade, mediado pelos fundamentos teórico. metodológicos da Atividade Orientadora de Ensino.

\section{As ações formadoras na atividade de formação}

A investigação que desenvolvemos, como já mencionamos, foi parte integrante de um projeto de pesquisa em rede que, desde sua concepção inicial, foi idealizado e organizado de acordo com a estrutura de uma atividade (MARCO et al., 2018). No desenvolvimento do projeto de modo colaborativo, com estudantes de graduação, professores da escola básica, mestrandos e doutorandos, buscava.se compreender os processos de formação pelas ações realizadas para a sua objetivação.

Foi nesse movimento de interação, integrados ao núcleo da Faculdade de Educação da Universidade de São Paulo, que nos propusemos a investigar o processo de significação da atividade de ensino de matemática dos professores que participavam do projeto, com o objetivo de identificar ações potenciais que incidem nessa significação.

Inserimo.nos como sujeitos no movimento de formação e fazíamos parte das decisões tomadas pelo grupo, de forma a pensar e agir na organização dos encontros, colocando.nos como sujeitos em atividade. Vale ressaltar que, durante o desenvolvimento das atividades de ensino, no movimento relatado na seção anterior, fizemos parte de um dos subgrupos e, em conjunto com os outros integrantes, desenvolvemos situações desencadeadoras de aprendizagem para o conceito de medida de tempo. 
A apreensão dos dados, portanto, foi realizada ao longo de todo o processo de formação desenvolvido durante 4 anos, totalizando 134 encontros semanais, nos quais foram registrados em vídeo as ações e as reflexões dos professores. Dentre elas identificamos as ações que consideramos formadoras, por incidirem no processo de significação da atividade de ensino de matemática dos professores, ou seja, porque são relevantes para compreender sua atividade de ensino.

Assim, apresentamos as ações orientadas a cada um dos objetivos propostos para a aprendizagem dos professores, expostos na Figura 4, que devem ser consideradas como parte de um todo no qual se encontram inter.relacionadas.

Figura 4 - Representação do dinamismo e da relação entre as ações potencialmente formadoras na atividade de formação contínua

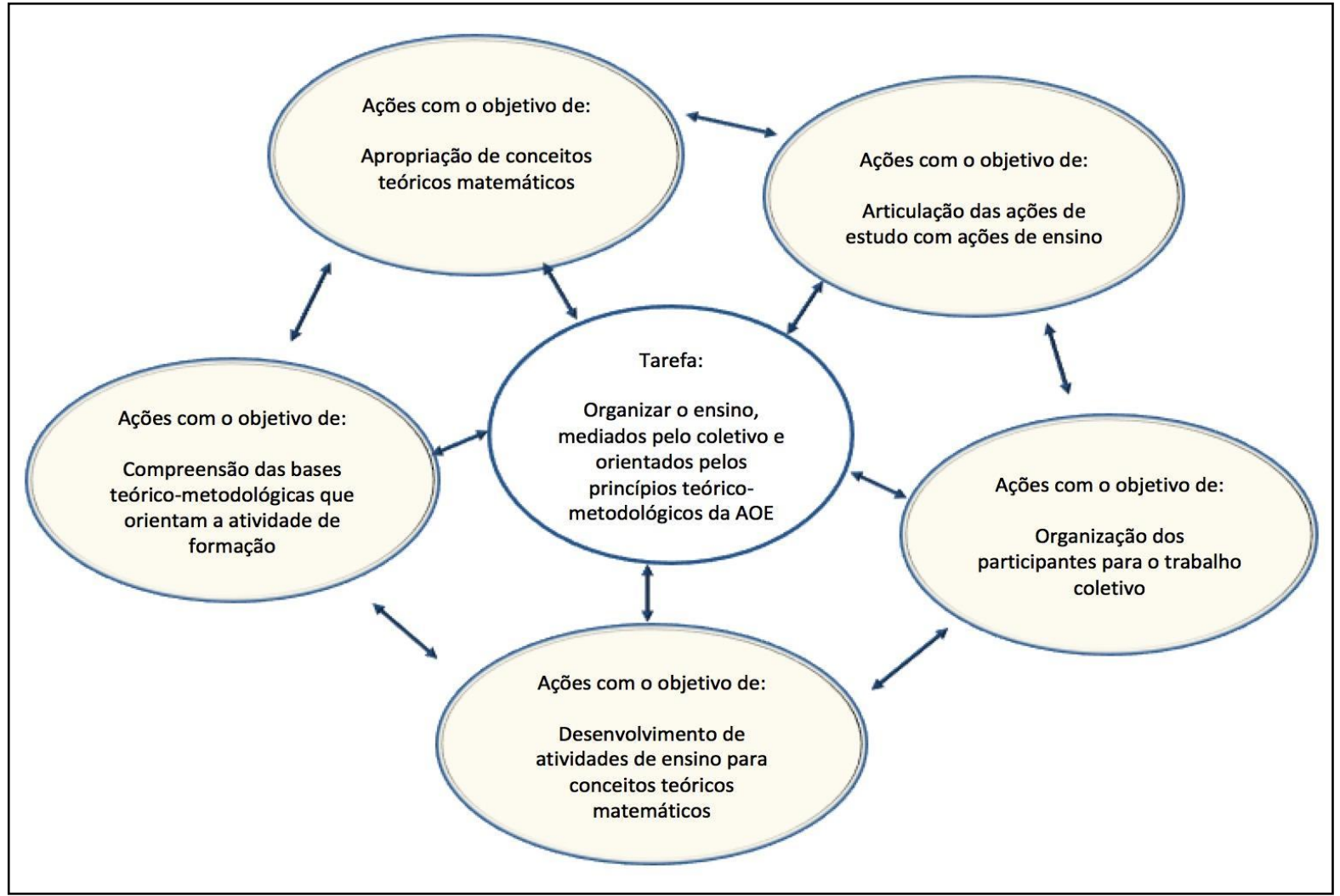

Fonte: Gladcheff (2015, p. 238)

A inter.relação entre as ações permite.nos colocar o movimento de formação como atividade, na perspectiva de Leontiev, ao serem compreendidas como uma unidade dinâmica, relacionando-se de forma dialética, em que os 
objetivos se intercalam continuamente. Por isso a impossibilidade de relacioná. las de maneira estanque, a cada elemento que compõe a essência do movimento de formação do pensamento teórico que, de acordo com Davidov (1988), envolve a análise, a reflexão e o plano interior das ações.

As ações que propomos (identificadas por A1 (Ação 1), A2, A3, ..., A24) e que estão alocadas de acordo com os cinco objetivos descritos pela Figura 4, encontram-se expostas no Quadro 1.

Quadro 1: Relação de ações propostas à atividade de formação

\begin{tabular}{|c|c|}
\hline Objetivo & Ações \\
\hline \multirow{3}{*}{$\begin{array}{l}\text { Compreensão das } \\
\text { bases teórico. } \\
\text { metodológicas que } \\
\text { orientam a } \\
\text { atividade de } \\
\text { formação }\end{array}$} & $\begin{array}{l}\text { A1- Ler, individualmente, textos relacionados a conceitos teóricos da Teoria histórico-cultural e } \\
\text { da teoria da atividade. }\end{array}$ \\
\hline & $\begin{array}{l}\text { A2- Participar de sínteses expositivas no/pelo grupo sobre conceitos teóricos da Teoria histórico- } \\
\text { cultural e da teoria da atividade, desenvolvidas por um ou mais integrantes do grupo de formação. }\end{array}$ \\
\hline & $\begin{array}{l}\text { A3- Discutir, coletivamente, sobre conceitos teóricos da Teoria histórico-cultural e da teoria da } \\
\text { atividade. }\end{array}$ \\
\hline \multirow{8}{*}{$\begin{array}{l}\text { Apropriação de } \\
\text { conceitos teóricos } \\
\text { matemáticos }\end{array}$} & A4- Ler, individualmente, textos relacionados a conceitos teóricos matemáticos. \\
\hline & $\begin{array}{l}\text { A5- Participar de sínteses expositivas no/pelo grupo sobre conceitos teóricos matemáticos, } \\
\text { desenvolvidas por um ou mais integrantes do grupo de formação. }\end{array}$ \\
\hline & A6- Sistematizar ações mentais relativas a conceitos teóricos matemáticos. \\
\hline & $\begin{array}{l}\text { A7- Ler, individualmente, textos sobre a história da matemática e sua influência no } \\
\text { conhecimento humano. }\end{array}$ \\
\hline & $\begin{array}{l}\text { A8- Discutir coletivamente sobre a história da necessidade humana que fez com que um } \\
\text { conhecimento matemático fosse criado. }\end{array}$ \\
\hline & A9- Discutir coletivamente sobre a lógica formal de um conceito teórico matemático \\
\hline & $\begin{array}{l}\text { A10- Resolver coletivamente um problema desencadeador de aprendizagem, para um conceito } \\
\text { teórico matemático. }\end{array}$ \\
\hline & A11- Participar de oficina pedagógica, manipulando materiais pedagógicos. \\
\hline \multirow{5}{*}{$\begin{array}{l}\text { Articulação das } \\
\text { ações de estudo com } \\
\text { as ações de ensino }\end{array}$} & A12- Relatar experiências vivenciadas na escola e na sala de aula. \\
\hline & A13- Ler, individualmente, textos relacionados a ações de ensino para conceitos teóricos matemáticos. \\
\hline & $\begin{array}{l}\text { A14- Participar de sínteses expositivas sobre textos relacionados a ações de ensino na perspectiva da } \\
\text { Teoria histórico-cultural, desenvolvidas por um ou mais integrantes do grupo de formação. }\end{array}$ \\
\hline & $\begin{array}{l}\text { A15- Discutir coletivamente textos relacionados a ações de ensino na perspectiva da Teoria } \\
\text { histórico-cultural. }\end{array}$ \\
\hline & $\begin{array}{l}\text { A16- Discutir coletivamente sobre os princípios teórico-metodológicos da atividade orientadora } \\
\text { de ensino. }\end{array}$ \\
\hline
\end{tabular}




\begin{tabular}{|c|c|}
\hline \multirow{4}{*}{$\begin{array}{l}\text { Organização dos } \\
\text { participantes para } \\
\text { o trabalho coletivo }\end{array}$} & A17- Compor subgrupos para realizar ações que fazem parte dos encontros de formação. \\
\hline & A18- Planejar o calendário e ações para os encontros de formação. \\
\hline & A19- Sistematizar apresentações sobre o que foi produzido durante os encontros de formação. \\
\hline & A20- Registrar o desenvolvimento de cada encontro de formação. \\
\hline \multirow{4}{*}{$\begin{array}{l}\text { Desenvolvimento } \\
\text { de atividades de } \\
\text { ensino para } \\
\text { conceitos } \\
\text { matemáticos }\end{array}$} & $\begin{array}{l}\text { A21- Elaborar, em subgrupos, um problema desencadeador para a aprendizagem de um conceito } \\
\text { teórico matemático, após ter estudado o movimento lógico.histórico do conceito. }\end{array}$ \\
\hline & $\begin{array}{l}\text { A22- Apresentar para o grupo de formação uma situação desencadeadora de aprendizagem para } \\
\text { um conceito teórico matemático, elaborada por subgrupos. }\end{array}$ \\
\hline & $\begin{array}{l}\text { A23- Desenvolver na escola uma situação desencadeadora de aprendizagem, planejada durante } \\
\text { os encontros de formação. }\end{array}$ \\
\hline & $\begin{array}{l}\text { A24- Relatar, ao grupo de formação, a experiência obtida com o desenvolvimento de uma } \\
\text { situação desencadeadora de aprendizagem na escola. }\end{array}$ \\
\hline
\end{tabular}

Fonte: Munhoz e Moura (2019, p.81-82)

Com as ações de $\mathrm{A} 1$ a A3, direcionadas à compreensão das bases teórico. metodológicas que orientam a atividade de formação, os integrantes do processo estabelecem uma relação entre o que está sendo proposto pela base teórica que fundamenta o processo e o que é realizado pelo grupo. Dessa forma, os sujeitos atribuem sentido às ações organizadas e praticadas durante a atividade de formação, compreendendo o significado social da atividade pedagógica construído coletivamente, segundo a perspectiva teórica que orienta tal formação.

As ações de A4 a A11, orientadas à apropriação de conceitos teóricos matemáticos, permitem compreender o conhecimento matemático em sua forma teórica, como uma produção sempre em desenvolvimento, que parte das necessidades humanas e reflete as leis do mundo que nos rodeia, servindo como potente instrumento para o conhecimento e o domínio da natureza em uma dimensão de ferramenta simbólica (ALEXANDROV, 2016; MOURA, 2013). A apropriação dos conceitos com esta perspectiva possibilita ao professor desfrutar de uma nova ferramenta, um novo instrumento para agir com mais segurança na sua atividade laboral (LANNER DE MOURA; SOUSA, 2002).

As ações de A12 a A16, destinadas a articular as ações de estudo com as de ensino, colocam os professores em um processo de reflexão e análise sobre suas ações praticadas no ambiente escolar e diretamente vinculadas às ações de estudo na atividade de formação. Dentre essas ações, encontram.se a abordagem e o 
debate sobre os princípios teórico.metodológicos que caracterizam a Atividade Orientadora de Ensino, a fim de que os professores os compreendam e se conscientizem de seu potencial formador.

Ao participarem de uma formação desenvolvida como uma atividade na perspectiva de Leontiev, os professores devem ser sujeitos de suas ações e, por isso, participar das decisões tomadas pelo grupo. Isso fica evidenciado pelas ações de A17 a A20, orientadas à finalidade de organizar os participantes para o trabalho coletivo, embora todas as outras ações tenham também esta referência. Isso porque o grupo de formação se torna um coletivo pela "interação e inter.relações das pessoas, mediadas pelos fins, tarefas e valores da atividade comum, o que vale dizer, por seu verdadeiro conteúdo" (PETROVSKI, 1984, p. 37, tradução nossa). Essas ações possibilitam aos professores conscientizar.se da relevância do planejamento de suas ações em todos os momentos de sua atividade de ensino, incluindo suas próprias ações no grupo de formação e na sua atividade laboral, pois a condição de trabalho coletivo os coloca em um movimento de criação e relações sociais, capazes de orientálos na realização de ações no interior dessa atividade humana (FRANCO, 2015).

Por fim, ressaltamos as ações de A21 a A24, orientadas ao desenvolvimento de atividades de ensino para conceitos matemáticos, como constituintes do elemento essencial no movimento de formação contínua, por possuírem uma relação direta com a principal ação da atividade de ensino do professor: planejar e desenvolver atividades de ensino que se concretizam na escola. Nesse processo, mediado pelo coletivo proporcionado pela atividade de formação e baseando.se nos princípios teóricometodológicos que a fundamentam, o professor se forma ao mesmo tempo em que forma seus estudantes e seus pares. Ao relatar para o grupo a experiência vivenciada na escola, o professor realiza um movimento de reflexão, análise e avaliação de suas ações, remodelando.as de acordo com as necessidades que surgem no decorrer do processo.

\section{Comentários finais}

Foi possível perceber, no decorrer da investigação, que os professores vislumbravam na atividade de formação, por meio das ações que eram realizadas, 
a perspectiva de satisfação de suas necessidades, o que, para Leontiev (1983), traduz.se no elemento que inicia ou impulsiona a atividade. Desse modo, os professores compreendiam a atividade de formação como um processo de significação de sua atividade de ensino, constitutiva de seu desenvolvimento profissional. A realização das ações do projeto era considerada como suporte e meio para mudança das práticas educativas, embora, nos ambientes de trabalho, enfrentassem condições adversas para desenvolvê.las.

Assim, ao finalizarmos este texto, ressaltamos que as ações elencadas, que podemos incorporar para o desenvolvimento da formação de professores, propostas pela investigação, atribuem à atividade de formação a possibilidade de desencadear o processo de significação da atividade de ensino do professor que ensina matemática. Uma significação mediada pelos princípios teórico. metodológicos da Atividade Orientadora de Ensino, que convirja na direção do significado social da atividade de ensino, como uma construção coletiva fundamentada nos pressupostos da teoria histórico-cultural.

$\mathrm{Na}$ atividade de formação, procuramos analisar a qualidade das ações de ensino e, para isso, observamos como os professores se mobilizavam e agiam, ao organizar o ensino orientados pelas ações que eram propostas. Entendemos que é por meio desse movimento coletivo que eles passam a explicitar o sentido que estão atribuindo à sua atividade de ensino e, com isso, defendemos a tese de que, em uma atividade de formação contínua de professores, na perspectiva da teoria histórico-cultural, a significação da atividade de ensino de matemática desenvolve.se nos sujeitos a partir das ações que realizam coletivamente para objetivar a aprendizagem teórica de conhecimentos matemáticos, ou seja, as ações potencialmente formadoras são aquelas que desenvolvem significação sobre o trabalho docente.

\section{Referências}

ALEXANDROV, A. D. Visión general de la matemática. In: ALEXANDROV, A. D. et al. La matemática: su contenido, método y significados. Madrid: Alianza, 2016. 
ARAUJO, E. S. Mediação e aprendizagem docente. In: Anais... CONGRESSO NACIONAL DE PSICOLOGIA ESCOLAR E EDUCACIONAL - ABRAPEE, 9., 2009, São Paulo - SP.

CARAÇA, B. J. Conceitos fundamentais da matemática. Revisto por Paulo Almeida. Lisboa: Gradiva, 2010.

CEDRO, W. L.; MOURA, M. O. Uma perspectiva histórico-cultural para o ensino de álgebra: o clube de matemática como espaço de aprendizagem. Zetetiké Revista de Educação Matemática, Campinas-SP, v.15, n.27, p. 37-56, jan./jun. 2007. DOI: https://doi.org/10.20396/zet.v15i27.8647015.

DAVÍDOV, V. La enseñanza escolar y el desarrollo psiquico. Tradução de Marta Shuare. Moscú: Editorial Progreso, 1988.

DAVYDOV, V. Tipos de generalización en la enseñanza. Ciudad de La Habana: Editorial Pueblo y Educación, 1982.

DIAS, M. S.; SAITO, F. Interface entre história da matemática e ensino: uma aproximação entre historiografia e perspectiva lógico-histórica. In: Anais... SEMINÁRIO INTERNACIONAL DE PESQUISA EM EDUCAÇÃO MATEMÁTICA, 2009, Brasília.

DUARTE, N. A individualidade para si. Campinas: Autores Associados, 1993.

FRANCO, P. L. J. O desenvolvimento de motivos formadores de sentido no contexto das atividades de ensino e de estudo na escola pública brasileira. Tese (Doutorado em Educação Escolar) - Universidade Federal de Uberlândia, Uberlândia, 2015.

GLADCHEFF, A. P. Ações de estudo em atividade de formação de professores que ensinam matemática nos anos iniciais. Tese (Doutorado em Educação) Universidade de São Paulo, São Paulo, 2015. DOI:

https://doi.org/10.11606/T.48.2016.tde-09032016-103554.

HOLZMAN, L. Pragmatismo e materialismo dialético no desenvolvimento da linguagem. In: DANIELS, H. (Org.). Uma introdução a Vygotsky. São Paulo: Loyola, 2002.

KOPNIN, P. V. A dialética como lógica e teoria do conhecimento. Rio de Janeiro: Civilização Brasileira, 1978.

LANNER DE MOURA, A. R.; SOUSA, M. C. O lógico-histórico: uma perspectiva didática da álgebra na formação de professores. In: ENCONTRO NACIONAL DE DIDÁTICA E PRÁTICA DE ENSINO, 11., Goiânia. Anais... Goiânia: ENDIPE, 2002. 
LEONTIEV, A. O desenvolvimento do psiquismo. Tradução de Manuel Dias Duarte. Lisboa: Livros Horizonte, 1978.

LEONTIEV, A. Actividad, conciencia, personalidad. Tradução Librada Leyva Soler, Rosario Bilbao Crespo e Jorge Garcia. Havana: Editorial Pueblo y Educación, 1983.

MARCO, F. F. et al. A constituição de um projeto formativo: implicações para o professor que ensina matemática. Educação Unisinos (online), v. 22, p. 298306, 2018.

MARTINS, L. M. A formação social da personalidade do professor: um enfoque vigotskiano. Campinas: Autores Associados, 2007.

MARTINS, L. M. Contribuições da psicologia histórico cultural para a pedagogia histórico-crítica. Exposição na Mesa-Redonda Marxismo e Educação: Fundamentos da Pedagogia Histórico-Crítica. In: COLÓQUIO INTERNACIONAL MARX E ENGELS, 7., IFCH, UNICAMP, 2012.

MARX, K. O capital: crítica da economia política. v.1. Rio de Janeiro: Civilização Brasileira, 2002.

MORETTI, V. D. Professores de matemática em atividade de ensino - uma perspectiva histórico-cultural para a formação docente. Tese (Doutorado em Educação) - Universidade de São Paulo, São Paulo, 2007. DOI: https://doi.org/10.11606/T.48.2007.tde-05102007-153534.

MORETTI, V. D.; MOURA, M. O. Professores de matemática em atividade de ensino: contribuições da perspectiva histórico-cultural para a formação docente. Ciência e Educação, Bauru, v.17, n.2, p.435-450, 2011. DOI: https://doi.org/10.1590/S1516-73132011000200012.

MOURA, M. O. A atividade de ensino como unidade formadora. Bolema, Rio Claro, v. 11, n. 12, p. 29-43,1996.

MOURA, M. O. A atividade de ensino como ação formadora. In: CASTRO, A. D.; CARVALHO, A. M. P. (Org.). Ensinar a ensinar: Didática para a Escola Fundamental e Média. São Paulo: Cengage Learning, 2012.

MOURA, M. O. A dimensão da alfabetização na educação matemática infantil. In: KISHIMOTO, T. M.; OLIVEIRA-FORMOSINHO, J. (Org.). Em busca da pedagogia da infância: pertencer e participar. Porto Alegre: Penso, 2013.

MOURA, M. O. (Org.). Educação escolar e pesquisa na teoria histórico-cultural. São Paulo: Loyola, 2017. 
MOURA, M. O. et al. Atividade Orientadora de Ensino: unidade entre ensino e aprendizagem. Revista Diálogo Educacional - PUCPR, v.10, n.29, p. 205-229, 2010. DOI: http://dx.doi.org/10.7213/rde.v10i29.3094.

MOURA, M. O.; ARAUJO, E. S. A atividade orientadora de ensino como mediação. In: BEATÓN, G. A. et al. (Org.). Temas escolhidos na psicologia histórico-cultural interfaces Brasil-Cuba, 2018.

MUNHOZ, A. P. G.; MOURA, M. O. Ações formadoras em atividade de formação contínua com professores que ensinam matemática nos anos iniciais da escolarização: uma iniciativa na perspectiva da teoria histórico-cultural. Revista Paranaense de Educação Matemática, Campo Mourão, PR, v.8, n.15, p. 62-88, jan.jjun. 2019. DOI: https://doi.org/10.33871/22385800.2019.8.15.62-88.

NASCIMENTO, C. P. A atividade pedagógica da educação física: a proposição dos objetos de ensino e o desenvolvimento das atividades da cultura corporal. Tese (Doutorado em Educação) - Universidade de São Paulo, São Paulo, 2014. DOI: https://doi.org/10.11606/T.48.2014.tde-01102014-105809.

PETROVSKI, A. V. Personalidad, actividad y colectividad. Buenos Aires: Editorial Cartago, 1984.

POLINOVA, N. Particularidades da solução de um problema combinatório por estudantes em atuação de cooperação. In: GARNIER, C.; BERDNARZ, N.; ULANOVSKAYA, I. (Org.). Após Vygotsky e Piaget: perspectivas social e construtivista. Escolas russa e ocidental. Porto Alegre: Artes Médicas, 1996.

ROSA, J. E.; MORAES, S. P. G.; CEDRO, W. L. As particularidades do pensamento empírico e do pensamento teórico na organização do ensino. In: MOURA, M. O. (Org.). A atividade pedagógica na teoria histórico-cultural. Brasília: Liber livro, 2010.

RUBTSOV, V. A atividade de aprendizado e os problemas referentes à formação do pensamento teórico dos escolares. In: GARNIER, C.; BERDNARZ, N.; ULANOVSKAYA, I. (Org.). Após Vygotsky e Piaget: perspectivas social e construtivista. Escolas russa e ocidental. Porto Alegre: Artes Médicas, 1996.

SAVIANI, D. Pedagogia histórico-crítica: primeiras aproximações. Campinas: Autores Associados, 2011. (Coleção educação contemporânea).

SMOLKA, A. L. B. O (im)próprio e o (im)pertinente na apropriação das práticas sociais. Caderno CEDES, Campinas, v.20, n.50, p. 26-40, 2000. DOI: https://doi.org/10.1590/S0101-32622000000100003. 
SOUSA, M. C. O movimento lógico-histórico enquanto perspectiva didática para o ensino de matemática. Obutchénie: Revista de Didática e Psicologia Pedagógica, v. 1, n. 4, p. 40-68, 2018. DOI:

https://doi.org/10.14393/OBv2n1a2018-3.

SOUSA, M. C.; MOURA, M. O. O movimento lógico-histórico em atividades de ensino de matemática: unidade dialética entre ensino e aprendizagem. In:

Anais... ENCONTRO NACIONAL DE EDUCAÇÃO MATEMÁTICA, 12., São Paulo. Anais... São Paulo: ENEM, 2016.

SOUSA, M. C. et al. Do movimento lógico e histórico à organização do ensino: o percurso dos conceitos algébricos. Campinas, SP: Mercado de Letras, 2014. (Série Educação Matemática)

SOUZA, N. M. M.; ESTEVES, A. K. Busca de superação das contradições da forma escolar no movimento de formação contínua de professores que ensinam matemática. Obutchénie: Revista de Didática e Psicologia Pedagógica, v. 2, n. 3, p. 669-697, 2018. DOI: http://dx.doi.org/10.14393/OBv2n3.a2018-47440.

VIGOTSKI, L. S. Psicologia pedagógica. Tradução de Paulo Bezerra. 2. ed. São Paulo: Martins Fontes, 2004. (Psicologia e pedagogia).

VIGOTSKI, L. S. A construção do pensamento e da linguagem. Tradução de Paulo Bezerra. 2. ed. São Paulo: WMF Martins Fontes, 2009. (Biblioteca pedagógica).

VYGOTSKI, L. S. Obras escogidas. Madrid: Aprendizaje Visor y Ministerio de Educación y Ciencia, 1991. Tomo I. 